\title{
It's All Very Well for You to Talk! Situationally Disqualifying Ad Hominem Attacks
}

\author{
ERIK C.W. KRABBE Rijksuniversiteit Groningen \\ DOUGLAS WALTON University of Winnipeg
}

Key Words: Fallacies; argumentation; ad hominem arguments; personal attack; bias; poisoning the well argument; character attack; pragmatic inconsistency.

Abstract: The situationally disqualifying $a d$ hominem attack is an argumentative move in critical dialogue whereby one participant points out certain features in his adversary's personal situation that are claimed to make it inappropriate for this adversary to take a particular point of view, to argue in a particular way, or to launch certain criticisms. In this paper, we discuss some examples of this way of arguing. Other types of ad hominem argumentation are discussed as well and compared with the situationally disqualifying type. The socalled Houtlosser Dilemma highlights the danger of unconditionally condoning ad hominem arguments. We propose a classification of ad hominem, and a more restrictive use of the term 'circumstantial'. Finally, we discuss whether ad hominem arguments are (always?) to be rejected as fallacious.

\section{Introduction ${ }^{1}$}

The argumentum ad hominem or "argument against the person" is the kind of argument whereby one participant in a dialogue uses a personal attack to attempt to discredit or refute the tenets or the argument of another participant. There are at least two standard or common ways to do this, and both of these ways have been widely recognized in logic textbooks as types of ad hominem arguments: One way is to attack the person directly, by arguing that she has a bad character, especially a bad character for veracity, and cannot therefore be trusted to be sincere or to be a reliable participant in the dialogue. The other way is to claim that what she advo- cates in her argument is a policy or opinion that is inconsistent with commitments determined by her own personal circumstances. The first kind of argument is called the 'abusive' or direct ad hominem and the second is called the circumstantial type of ad hominem argument. Some authors use other labels, such as tu quoque or poisoning the well to characterize types of personal attack. Sometimes such labels function merely as another name ( $t u$ quoque for the circumstantial type, for instance), sometimes as names for subtypes, or for alleged new types that do not fit in with either of the two standard types.

Indeed, it is not hard to think of cases of personal attack that are not easily described as either "abusive" or circumstantial. In this paper we want to introduce and briefly discuss one particular type of case that seems to have been neglected thus far. The following example may suffice as a first indication of what we are after in this paper:

CASE I [Holland, December 1990] A retired major general argues in front of his relatives that the Dutch government must give more substantial support to the allied efforts in the Gulf Area. "We ought to send ground forces," so he claims. His grandson retorts: "It's all very well for you to talk, grandpa! You don't have to go there."

The grandson's point (if he has a point!) is that grandpa's actual situation, his being a retired person who will not be sent out anyhow, disqualifies him (morally?) as a defender of the present point of view. We shall 
shortly present some other examples of this type of personal attack. But first we shall briefly survey the other types of ad hominem so that we may assign our type, which may be called situationally disqualifying ad hominem its proper place among them. We hope, in this paper, to make clear what is distinctive about the species, and to start the discussion about its fallaciousness as contingent upon different contexts of dialogue. ${ }^{2}$

\section{Varieties of Ad Hominem}

It is not at all easy to classify ad hominem arguments by sharp and unambiguous criteria. ${ }^{3}$ One can see already that the direct (abusive) and the circumstantial types overlap in some cases. Often, for example, the circumstantial argument is used as a kind of lead-in attack which is then extended or developed into a direct ad hominem attack. In such a case, the arguer's personal circumstances are said to be in conflict with his argument, implying that the arguer is therefore dishonest, insincere, hypocritical, or otherwise deficient in character for veracity.

CASE 2 [December 1990] In a panel debate about whether or not, ultimately, force should be used to enforce the U.N. resolutions about Kuwait, a politician defends the point of view that this may be necessary to maintain international legal order and justice. His adversary, a journalist, opposes this view. "You weren't talking this way as the U.N. were passing resolutions about the Palestinians. Whence this sudden concern for international law?" She then expands this argument, insisting on the parallelism between the two cases, and on the politician's complete lack of concern for the enforcement of previous U.N. resolutions. "In view of this," she concludes, "we may wonder whether you are the one to teach us a lesson about justice." At that moment the chair stops her.
Case 2 shows how a circumstantial ad hominem argument may underly, and shift into, a direct personal attack. It is easy to imagine that, but for the chairperson's interference, this direct attack could have continued by further alleged examples of the politician's lack of justice.

A third variant of the ad hominem argument is the bias type of attack, where one arguer claims that the other is not an impartial or honest proponent of her point of view because she has personal commitments or interests at stake, or something to gain, financially or otherwise, by supporting that point of view.

CASE 3 a. In the panel debate of Case 2 the
journalist remarks that this poli-
tician is just following the party
line.
b. The journalist remarks that her
adversary's point of view will
"no doubt gain him a lot of
votes."
c. The journalist points out that the
politician has just bought an
enormous quantity of stock of
an important arms industry that
stands to make profit in case of
war.
d. The journalist urges that the pol-
itician, being a member of his
party, can never objectively as-
sess the pro's and con's of the
matter.

This type of personal attack, which can often seriously damage the credibility of one's adversary, is distinct from either of the two standard types. Unlike with the direct (abusive) personal attack there need not be an assault on one's adversary's character. Of course there may be mergers with, or shifts into, the direct type of ad hominem: It is not hard to imagine how Case $3 c$ could develop into pure abuse. But, with the bias type of ad hominem, character, whether character in general, or more specifically character for veracity, is not the issue. What is under attack is one's adversary's aptitude to be a serious and sincere discussant in this particular 
dialogue. Circumstances are adduced that would lead to doubt about this aptitude. In this respect the bias type is similar to the circumstantial type. But in another respect the bias type is rather the opposite of the circumstantial type. Whereas in the circumstantial ad hominem one tries to construe the position of the other party as inconsistent, a bias type of attack, paradoxically, decries the overwhelming consistency that obtains between a discussant's affiliations and interests and his expressed point of view.

A particularly harsh subspecies of the bias type is exemplified by Case $3 \mathrm{~d}$. This is the poisoning the well type of ad hominem, where the arguer attacked is said to be so dogmatic, fanatical, or dishonest that nothing he might say can ever be trusted as reliable. This is an extreme form of ad hominem attack which appears to leave the attacked party no room available at all for defence or further participation in the dialogue. The implication is that this person is so slippery or duplicitous that you can never really engage in a serious discussion with him at all. It has the effect of excluding the participant from the dialogue tout court.

Sometimes the term poisoning the well is used to cover all the cases of the bias type. Whatever terminology one prefers, it seems useful to distinguish attacks like Case $3 \mathrm{~d}$ from the other, presumably less ambitious, ones. Case 3 a claims that the arguer is biased by a preset commitment, or at least looking at the issue from a particular point of view. In Case $3 \mathrm{~b}$ it is suggested that some personal gain is involved which blocks an open-minded dialectical interchange. In Case $3 c$ this gain is financial, and the charge may easily be developed into a severe attack on character. But in none of these cases is the threat to a fruitful continuation of the dialogue as great as it is with Case $3 \mathrm{~d}$.

There are many subspecies of the circumstantial ad hominem. According to our definition, a circumstantial ad hominem attack consists of an attempt to point out an inconsistency in the arguer's position. Part of this position consists of propositions that were explicitly or implicitly asserted within the dialogue. If nothing more is used, one would not, usually, speak of a circumstantial ad hominem. Pressing a man with the consequences of what he himself, within the same context of dialogue, has granted to be the case may, appropriately, be called a Lockean ad hominem (after John Locke, who described the genre). A Lockean ad hominem is in itself an impeccable way of arguing, even though defeating one's adversary in this way may lead one to an exaggerated estimate of the solidity of one's own point of view. It is typical for the circumstantial $a d$ hominem, however, that part of the propositions that constitute an arguer's alleged position are inferred from circumstances. This may be done in several ways: (i) one may adduce assertions made by the same adversary in other circumstances (Case 4a, below); (ii) one may adduce assertions that were never explicitly made by one's adversary himself, but to which he appears to be committed by virtue of his affiliation to some party or group (Case 4 b), or (iii) one may infer particular points of view from one's adversary's present or previous actions (Case $4 \mathrm{c}$; this includes silence on an issue, as in Case 2).

CASE 4 a. Like Case 2 ; the journalist points out that the politician had been opposed to the enforcement by armed troops of a U.N. resolution about Korea.

b. The journalist wonders how the politician, as a member of the Christian Committee for Peace, can hold on to this point of view.

c. The journalist points out that the politician used to be a conscientious objector.

The label tu quoque ("you too") is often used as a synonym for what is here called the circumstantial ad hominem. For instance, Woods and Walton (1977) distinguish four types of what they call $t u$ 
quoque according to the way one is to construe the inconsistency in the position of the arguer thus attacked. ${ }^{4}$ It is also possible to have a more stringent signification for the term tu quoque. In this restricted sense, tu quoque denotes just those cases of the circumstantial ad hominem where the critic replies to a previous ad hominem attack by saying something to the effect of: "What about you? You are just as bad yourself!" In principle, replying to one ad hominem argument with another is not unreasonable-in some cases this is a highly effective and appropriate type of response-but all too often such personal ripostes are a sign of a shift to a quarrel.

Having surveyed these different types of ad hominem we may now state a negative result about situational disqualification, the type of ad hominem exemplified by Case 1: it cannot be subsumed under any of these extant types. Let us have a second look at Case 1 to make this clear. First, there is no assault on character (or character for veracity). Of course the attack in Case 1 could be further developed into a direct personal attack, but as we saw this holds for any indirect personal attack. The likelihood of such an extension is no reason to say that Case 1 in itself constitutes a direct ad hominem. Also, there is no inconsistency implied in the position of the major general. Here we have to be careful, and use the word 'position' in the same sense as we did when discussing the circumstantial ad hominem. An arguer's position is a set of propositions to which he is committed as may be inferred from the arguer's utterances, his affiliation, and his actions. ${ }^{5}$ The "it's all very well for you to talk"-argument in Case 1 does not suggest that there is anything wrong with the major general's position in this sense. Finally, it is not suggested or implied that there is a lack of impartiality on the major general's side. Rather, it is objected that the general's concern with the matter, now that he is retired, is too slight to make him a suitable partner in the dialogue.
On the other hand, Case 1 shows that situational disqualifiers display some similarities with each of the other types. The retired major general is blamed for having presented his argument in favor of sending ground forces to the Gulf area, so it may be claimed that at least one aspect of the general's character is criticized here: he should know better when to shut up. Also, even though there is no claim of inconsistency with respect to the general's position, the grandson may be said to claim that there is a clash of some sort between the general's situation and his argument. Third, if the group of people that have no chance to be sent to the Gulf is, somewhat forcefully, constructed as a party with views and interests of its own, Case 1 comes pretty close to Case 3 a.

\section{The Houtlosser Dilemma}

In this section, we shall have a closer look at the bias type of ad hominem argument, which is in many respects similar to the situationally disqualifying type. In a sense, bias arguments form themselves a subspecies of situational ad hominem arguments. (But we shall presently propose a stipulative definition of situational ad hominem argument that will keep the two apart.)

What is so bad about the bias argument? Often they seem dialectically strong and rhetorically effective. One tempting point of view is to say that the more severe type of bias ad hominem argument, illustrated by Case $3 \mathrm{c}$ for instance, is such a powerful kind of attack that it cuts off further dialogue altogether. No matter what the politician says, because of his financial involvement, his argument is bound to be discredited. It may seem to follow then, that in this kind of case, the ad hominem argument is fallacious, because it leaves the politician no further room to argue. So conceived, this ad hominem argument would be a "situationally disqualifying" 
argument (because of the politician's financial involvement) that "poisons the well" by cutting off the possibility of further credible argumentation by the politician in the dialogue.

There is something in this situation hat can be brought out by examining the case of the bias type of ad hominem attack below, taken from Walton (1989, p. 149).

\section{CASE 5 Bob and Wilma are discussing the problem of acid rain. Wilma ar- gues that reports on the extent of the problem are greatly exaggerat- ed and that the costs of action are prohibitive. Bob points out that Wilma is on the board of directors of a U.S. coal company and that therefore her argument should not be taken at face value.}

Bob is suggesting that Wilma is not a sincere participant in the critical discussion on acid rain because of her financial involvement with the coal company. Assuming that Wilma did not, at the beginning of the discussion, inform the other participants of this involvement, Bob's criticism that she is biased is a powerful attack on her sincerity. In the acid rain case, the ad hominem attack on Wilma's arguments, on the ground that she is biased, seems at face value to be a reasonable type of ad hominem argument, and not a fallacious use of this type of argumentation. We would say, in this case, that the ad hominem argument against Wilma is a valuable contribution to the dialogue and, in that sense, a good argument. But we have to be careful in judging just how good a contribution it really is. The ad hominem argument is such an overpowering argument in many cases precisely because it is very easy to overestimate its weight, and think of it as a decisive refutation-a kind of "last word" that leaves no room for reply or defense.

If you look at the situation from Wilma's point of view, you can see that the initial situation is not very favorable for her. She is on the board of a coal company, and she has to take some stand in the critical discussion on acid rain. Whatever point of view she takes in this discussion, she will be in a vulnerable position.

The difficult situation exhibited by this type of case represents a general problem called the Houtlosser Dilemma, represented by Figure 1 below. ' $\mathrm{BCC}$ ' represents the initial situation, where Wilma is on the board of a coal company.

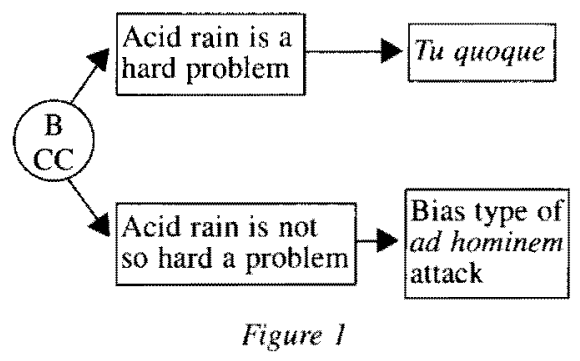

Given that Wilma is on the board of the coal company in the first place, she is in a bad fix no matter which way she tries to argue. If she tries to argue that acid rain is not a hard problem, then, as we saw, she is open to a bias type of ad hominem attack (especially if she conceals her relationship with the coal company). However, if she were to try to argue for the opposite point of view, and take up the thesis that acid rain is a hard problem, curiously, she would be open to the $t u$ quoque type of $a d$ hominem attack-her critics could say that she is arguing it is a hard problem, one that presumably ought to be corrected or eliminated, while in fact she is contributing to that problem herself by working for the coal company. She is between a rock and a hard place.

The moral seems to be a bit paradoxical: never join the board of a coal company (some people may actually like this conclusion), but, if you do, don't get involved in a critical discussion on acid rain. This would mean that certain people are excluded from participating in a discussion on certain issues.

The dilemma is that if you are in a situation like Wilma's, you seem to invite an ad hominem attack whatever you say. The 
situation seems to leave you no room to argue at all, at least not in an inoffensive way. When you are in a Houtlosser Dilemma, it is as though the "well is poisoned," because you have no way of carrying on with a line of argument that cannot be closed off by ad hominem attacks.

The solution to the Houtlosser Dilemma is to recognize that, in this type of case, the argumentum ad hominem makes sense as a contribution to the discussion, and therefore may be thought of as a good (nonfallacious) type of argument, but also that it is a type of argumentation that is inherently defeasible, and that one should not allow such arguments to close off the dialogue altogether. Some room must be left for Wilma to reply successfully.

For example, in the present case, Wilma might hold that acid rain is a bad problem, and concede that the the coal company is contributing to that problem, but add that she and the others on the board are trying to do something about it. Some room must be left open, in principle, for this line of argument, or one like it, to be successful in carrrying the dialogue further.

Similarly, if Wilma's position is that acid rain is not so bad a problem, she might concede that this point of view is more or less to be expected from someone on the board of a coal company, but add that such happens to be the outcome of a recent investigation conducted by an independent agency. Again, in good dialogue, such a line of defense should be given a hearing.

In short, what we should recognize in this type of case is that the effect of the $a d$ hominem argument in a context of dialogue is such that (in accord with reasonable rules of dialogue) it shifts a burden of presumption against the proponent, but we should regard the burden as one that can be met. The ad hominem is a defeasible type of argument that, correctly used, does shift a weight of presumption against a participant in dialogue. But we must not overestimate that weight by thinking of it as sealing off the dialogue.

\section{The Discredit the Non-Victim Argument}

To gain a better understanding of what is involved in a situationally disqualifying ad hominem attack (or situational ad hominem for short), we shall quote a case discussed by Steven Lukes (1987). The case is taken from an interview of Mrs. Thatcher, about her South Africa policy, with Hugo Young, published in The Guardian:

CASE 6 We now approached the central thrust of the prime ministerial argument, that part of it which elicited her most withering scorn.... The matter in question was the moral case for sanctions. "I must tell you I find nothing moral about people who come to me, worried about unemployment in this country, or about people who come to us to say we must do more to help Africa-particularly black Africans. I find nothing moral about them sitting in comfortable cicumstances, with good salaries, inflation-proof pensions, good jobs, saying that we, as a matter of morality, will put $\mathrm{x}$ hundred thousand black people out of work, knowing that this could lead to starvation, poverty and unemployment, and even greater violence." I tried to intervene. "So the black leaders who..." But Mrs. Thatcher was thumping the table." That to me is immoral. I find it repugnant. We had it at the Community meeting. Nice conference centre. Good jobs. And you really tell me you'll move people around as if they are pawns on a checkerboard, and say that's moral. To me it's immoral."

As Steven Lukes points out, there are two arguments ad hominem here, arguments "which seek to undermine the case for sanctions by attacking its advocates." According to the first ad hominem, which is called the Discredit the Non-Victim Argument by Lukes, the advocates of sanctions "are held to be in no position to argue their case, because of their own distance or 
immunity from their effects. They stand accused of, in effect, advocating the suffering of others, whom they thereby treat like 'pawns on a checkerboard.' Presumably, then, only the potential sufferers from sanctions have the right to make the case" (1987:179). The second ad hominem is a circumstantial one: it is suggested that there is some sort of inconsistency in advocating sanctions for those that are "worried about unemployment in this country" or saying "we must do more to help Africa...". Steven Lukes speaks of the Discredit the Inconsistent Argument.

This case illustrates, among other things, how different species of ad hominem may be intertwined in one argumentative text. At present we are mainly interested in the Discredit the Non-Victim Argument, which may easily be identified as a situational disqualifier, analogous to the one we saw in Case 1 . In both Case 1 and Case 6 , it is claimed that a certain arguer who advocates a certain policy (a course of action) may be disqualified because he will not suffer from this policy, if it is put through, whereas others will. Case 6, however, has moral overtones that Case 1 has not. Mrs. Thatcher seems to hold that to advocate sanctions from a comfortable distance is immoral. In Case 1 there is a charge of incongruity or impropriety, but 'immorality' would be to strong a term.

Steven Lukes does not see any force in the Discredit the Non-Victim Argument. He formulates two general objections: "First, ... it would prohibit most people from taking moral stands on many issues; second, ... it is the responsibility of politicians to take a stand on just such issues as this; .... ${ }^{18}$ As these objections show, a general admission of situational disqualifiers would have a detrimental effect on the possibilities of dialogue. But are we facing a type of fallacy, or merely a weak, defeasible, type of argument? We shall return to this question shortly.

\section{Other Disqualifiers}

We have seen that a situational disqualifier does not necessarily involve a claim of moral impropriety. But we may generalize a bit more: the ground for disqualification may be quite different from that in the Discredit the Non-Victim Argument. The issue need not even be a policy or practical measure.

CASE 7 a. A schoolboy is accused of some act of vandalism. As the headmaster is about to probe for the boy's motives, one of the boy's friends tries to get a word in between, arguing that the accused couldn't help it. But the headmaster stops him short, "since this young man is quite able to speak for himself."

b. A lawyer has taken on to defend an alleged crook. It is a very complicated affair with all kinds of financial manipulations that are hard to unravel. By a clever argument the lawyer succeeds in giving a plausible interpretation to the pile of evidence. Unfortunately, the only possible conclusion seems to be that his client is guilty. The judge then dismisses the argument, claiming that the lawyer's task is to defend his client, not to prove his guilt.

In view of such examples, we prefer to extend the use of the term situational ad hominem so as to include them. For, even though in these cases there is no advocacy of a policy from which the arguer would not suffer, but others would, they are clearly examples of ad hominem attacks that aim at a situational disqualification, and that are, moreover, hard to subsume under any other type of ad hominem. The next disqualifier brings us close to the direct or "abusive" ad hominem:

CASE 8 Grandpa and grandson are discussing the situation in some distant country. Grandson claims that the regime in that country is immoral, because of its racist policies. He 
argues that the regime should be replaced. Grandpa dismisses the argument, because grandson has never been to that country, and therefore cannot have an adequate judgment of the situation there.

Grandpa's attack is aimed at the lack of expertise on the side of his grandson. Such arguments have often been included among the direct ("abusive") ad hominem attacks (e.g., Woods and Walton, 1977). We have laid it down that an abusive or direct ad hominem is a personal attack on one's adversary's character, especially character for veracity. Grandpa's attack does, indeed, concern his grandson's trustworthiness or veracity, but only with respect to the specific issue under debate. Grandpa does not claim that his grandson has a bad character (for veracity) in general. Therefore, we propose to include this attack among the situational disqualifiers, rather than among the direct ad hominem attacks. (Of course, grandpa could go on and extend the argument to an attack on character, as well as to a poisoning the well type of ad hominem.)

\section{A System of Classification}

At this point we, tentatively, propose the following definition of the situational ad hominem: the situationally disqualifying ad hominam attack (or, situational ad hominem) is an argumentative move in dialogue whereby one participant points out certain features in his adversary's personal situation that are claimed to make it inappropriate for this adversary to make a certain dialectical contribution. The dialectical contribution in question may, for instance, consist of a statement of a particular view, or of a presentation of a particular argument in favour of this view, or of a particular criticism. The objectional features in one's adversary's situation may be such as to yield evidence for a lack of concem for, or a lack of insight in, the issue under debate, or of any other kind, with the exception of evidence for a positional inconsistency or a bias.

Subspecies of the situational ad hominem are the lack of concern ad hominem (including the Discredit the Non-Victim argument, Case 1 and Case 6) and the lack of insight (lack of information) ad hominem (Case 8). But there are also other subspecies, as shown in Case 7a and Case $7 \mathrm{~b}$.

Generally then, we see the situational ad hominem as a type in its own right, separate from the circumstantial type, the direct type, and the bias type of ad hominem argument. In this typology, we are deviating from the traditional treatments of ad hominem in textbooks. The textbooks, very broadly speaking, used to use the term 'circumstantial', as opposed to 'abusive' ad hominem, to cover quite a variety of arguments, where we made distinctions into different types. Doing so, we have used the term 'circumstantial' in a much stricter sense, to refer to only those cases where there is an (alleged) inconsistency involved in an arguer's position, and where this position is partly reconstructed from the arguer's circumstances. The traditional texts tended (although not consistently) to include bias and disqualifying situations as "circumstances", i.e., as targets for ad hominem attacks, but without any reconstruction of an inconsistency in the arguer's position. Thus part of the tradition tended to lump the bias and the situationally disqualifying type together with $t u$ quoque under the heading of circumstantial ad hominem arguments. Moreover, those traditional texts that did distinguish several types of "nonabusive" ad hominem (like tu quoque or poisoning the well) differed among themselves in their use of the term 'circumstantial ad hominem'.

Going against this tradition, we have confined the term circumstantial ad hominem to the narrower range of cases where some clash of propositions-an inconsistency, normally a pragmatic inconsistencyis essentially involved. Being wary of 
departing from tradition too radically however, we are ready to adapt our preferred terminology to tradition a little by distinguishing a wider and a narrower sense of 'circumstantial ad hominem'. Thus we have arrived at the system of classification in Figure 2.

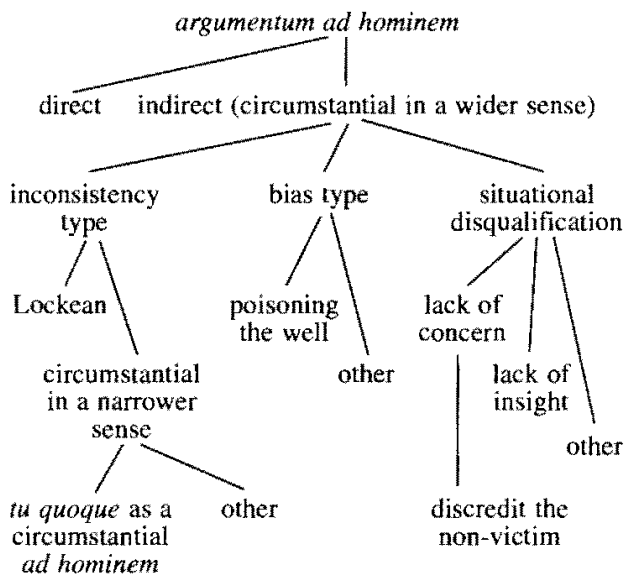

Figure 2

We really think the narrower type of circumstantial ad hominem argument has a special logic of its own, and that it is crucially important to distinguish carefully between it and the bias and situationally disqualifying types. Hence our preference for using the term 'circumstantial' in the narrower way, in our preferred system of classification. But we recognize that the burden of proof for this apparently radical position is heavy, given the linguistic evidence for applying the broad term 'circumstantial' to the bias type and situationally disqualifying type, as well as to the narrower range of cases characterized by an inconsistency. So we are willing to compromise, somewhat reluctantly, here.

\section{Fallaciousness}

Are ad hominem arguments fallacious? In our discussion of the Houtlosser Dilemma, we reached the conclusion that some types of ad hominem are (conditionally) nonfallacious. Does this conclusion hold for all types? Let us briefly study this question with respect to the different species of ad hominem we have distinguished.9

First, consider the direct or abusive ad hominem. In a way, the name 'abusive' is misleading, because this first type of ad hominem, though often straightforwardly irrelevant and fallacious, can be a reasonable argument in some instances. For example, in evaluating the testimony of a witness in legal cross-examinations, raising questions about the person's character, reliability as a witness, past convictions, and so forth, is regarded, within limits, as a legitimate kind of argumentation. So too, in election campaigning in political debates, raising questions of a candidate's personal integrity and character are recognized as legitimate, again within limits.

Brinton (1986) cites character as a positive factor that can be appealed to in argumentation, following Aristotle's remarks in the Rhetoric and Nicomachean Ethics that the good man's speech is more credible, especially where opinions are divided and certain knowledge that would resolve the issue is not available at the time. According to Brinton (1986: 246), an ethotic argument is an argument in which ethos (character) is used to transfer credibility, either positively or negatively, from persons to a conclusion. If ethos is a legitimate factor in argumentation, it would seem to follow that the direct ad hominem type of argument can itself be a legitimate kind of argument in some cases.

The same thing could be said about the circumstantial ad hominem. Suppose a politician has gone on record as advocating keeping government expenses down by not giving out inflationary salary raises to government officials, but it is later revealed that, once elected, he has given himself a large increase to his already sizable salary. A critic may then say "You do not practise what you preach!", using the circumstantial type of ad hominem argument against the politician. In such a case, the ad hominem 
argument could be a quite reasonable contribution to the discussion. Only if it is carried to excess in some way, or used to seal off the dialogue, would it become fallacious. Thus we have already remarked that the tu quoque (which is a kind of circumstantial ad hominem) may be indicative of a shift to a quarrel. The fallacy in such cases is a kind of illicit dialectical shift away from a critical discussion (discussion aiming at a reasonable resolution for a conflict of opinion) towards a personal quarrel. Quarrelling, though it may have its own advantages, is not an efficient way of contributing to the reasonable resolution of a conflict. Therefore, from the vantage point of norms and rules for critical discussion, such a shift is fallacious.

Generally, the ad hominem fallacies can be analyzed as a dialectical failure, that is, a failure of an argument to meet requirements of a formal structure of dialogue ${ }^{10}$ But dialogues of different types require different structures. ${ }^{11}$ This means that what may be described as a fallacy from one perspective (one type of dialogue) need not be fallacious from another one. For instance, the ad hominem attack by the journalist in Case 2 may well be fallacious according to the rules of some tightly structured system for critical dialogue, and yet perfectly reasonable in the context of a televised debate, where the goal is perhaps not so much to resolve a conflict between the direct participants as to make an impression on the audience. Within the framework of a Lorenzen dialogue (a type of dialogue with a particular formal structure), Barth and Martens (1977: 84), interpreting a text of Whately's (1829: 20lf.), describe two kinds of what may be called ad hominem fallacy as the following types of incorrect inference: (i) just because the proponent has defended his thesis, $T$, successfully against his opponent's criticism ex concessis (i.e., on the basis of the opponent's concessions), it does not necessarily follow that $T$ is "defendable against a person who makes the same concessions but who chooses another line of attack"; (ii) even if $T$ is so defendable, regardless of the lines of attack chosen by the opponent, "this does not guarantee the truth of $T$...." Notice that in this case it is not the ad hominem argumentation in the dialogue itself that constitutes the fallacy, for this will be a perfectly reasonable Lockean ad hominem, but the exaggerated consequences drawn from its success. Such exaggeration was called the basic ad hominem fallacy by Walton (1987: 318).12

In a particular case, there may be quite a number of factors to be taken into account in judging whether the given ad hominem argument is fallacious or not. A good case in point is the well-known smoking example, studied in detail in Walton (1985: 71):

\section{CASE 9 A parent gives a lecture to her son, arguing that smoking is very bad for your health, and that therefore one should not smoke. But the child replies, "What about you. You smoke. So much for your ar- gument against smoking!"}

In a case like this, we have to be very careful to try to interpret exactly what the child's conclusion is supposed to be. If the child is rejecting the parent's argument that smoking is bad for your health per se, then he could be committing a serious ad hominem fallacy. But if the child is only questioning the sincerity of the parent, seeing that she is not following her own advice, then he could be raising legitimate grounds for doubt concerning the practical consistency of the parent's commitments. And if the parent is inconsistent, why should the child take the data of the parent's lecture on trust? One can easily see from considering this kind of example that each case should be carefully considered on its merits. Sometimes the ad hominem argument should be rejected as a fallacy, while in other cases it is a reasonable kind of argument which can quite legitimately be used to raise critical questions or shift a burden of proof in a dialogue. 
Particularly in contexts of argument where hard evidence is insufficient to decide a case, and we have to depend on soft, defeasible kinds of arguments like witness testimony or appeal to authority, the ad hominem argument can often be a legitimate way of testing the credibility of a participant in dialogue. As such, it can be a nonfallacious kind of argumentation. ${ }^{13}$

The bias type of ad hominem displays the same possibilities of reasonable and fallacious uses. The suspicion of a bias or special interest may be a very great hindrance to a good and efficient argumentative exchange. Just as in the case of a pragmatic inconsistency, this suspicion will make one doubt whether one's adversary is seriously and sincerely cooperating in the critical discussion. In some such cases the bias attack can be very useful to shift the burden of proof to the other side, so that the air may be cleared. For instance, in Case $3 \mathrm{a}$ it may have been a good question to ask, whether the politician is giving his own views or merely mouthing those of his party. In other cases, however, the bias attack is just an attempt to seal off or obstruct the dialogue: it is not used to clear the air, but to force a dialectical shift, either to a critical discussion on another issue, or to some type of interchange that is no longer a critical discussion at all. This is certainly the case with the poisoning the well type of attacks, as in Case 3d. If a poisoning the well move is ever a reasonable move, this reasonableness must be determined from another perspective than that of critical discussion. From the latter perspective such a move is always fallacious.

As to their fallaciousness, and reasonableness, the situationally disqualifying $a d$ hominem attacks fare much like the poisoning the well attacks. From the perspective of norms and rules for critical discussion, we must condemn such attacks throughout. For, instead of furthering the dialogue, they tend to finish it off. In practice though, a disqualifier may sometimes constitute just a playful interlude, or a kind of joke, that doesn't really belong to the dialogue itself. In Case 1 the major general could perhaps appreciate his grandson's remark with a grin, and then go on to discuss the pro's and con's of sending out ground forces. In Cases $7 a$ and $7 b$, one may even be inclined to say that the disqualifiers are quite reasonable moves. But this has nothing to do with the norms and rules for critical discussion. In such cases our hunch that the move is innocuous, or even applaudable, originates from external considerations that make it advisable to cut off a particular dialogue or argument.

The idea behind the situational ad hominem as a reasonable action in dialogue is that in certain situations people are not in a position to express a particular point of view or criticism, or to argue in a particular way. They are not supposed, or not entitled, to do so. From the perspective of critical discussion this idea is to be rejected. ${ }^{14}$ Some may want to reject the idea throughout, and therefore spurn all use of situational disqualifiers. But even if one is willing to admit that, sometimes, such situations do occur, one should still be severely critical of situational ad hominem in most cases. It is a type of move that, like poisoning the well and other fallacious ad hominem attacks, tends to prematurely close the dialogue. So, if we cherish critical discussions and want to formulate rules and norms to guide them, the situational ad hominem attack, as a fallacy, must be ruled out by these rules and norms.

If the purpose of some dialogue is other than that of resolving a conflict by verbal means, different norms and rules apply. For example, both the grandson in Case 1 and Mrs. Thatcher in Case 6 have chosen an effective means to express their feelings, or to make an impression on a third party, etc. What is a fallacy from one perspective (critical discussion) can still be positively valued from other perspectives (eristics, debate, humour, drama, etc.). ${ }^{15}$ 


\section{Notes}

1 An earlier version of this paper (not including the Houtlosser Dilemma) appeared in Dutch: Krabbe and Walton (1991).

2 The species was brought to our attention by $\mathrm{T}$. van de Poel, who attended Krabbe's course on fallacies in the spring term of 1989. It is from his presentation, in that course, of Case 6 below that this paper originates. We are grateful to Mr. van de Poel for having shared his views with us, both in his term paper on ad hominem as well as in several discussions we had on this type of case. In particular we have made use of his ideas of "lack of concern" and "lack of in formation" as basic elements in the structure of many situational ad hominem arguments.

3 For a somewhat fuller introductory exposition we refer to Chapter 6 of Walton (1989).

Others (e.g. van Eemeren, et al., 1986: 28ff., van Eemeren and Grootendorst, 1987: 285), while using the term $u$ quoque in a similar way, employ the term circumstantial to cover what we have called the bias type of ad hominem attack. It may also be argued that the tu quoque is not restricted to ad hominem exclusively. We shall return to the issue of terminology and classification in Section 6.

5 It is not necessary, at present, to discuss the different types of commitment sets that together make up an arguer's position, see Walton and Krabbe (1994?).

6 This dilemma was pointed out by Peter Houtlosser at the Summer Institute in Argumentation at McMaster University, Hamilton, Ontario, in June 1991, during a discussion of Case 5 following Douglas Walton's presentation of a lecture on parts of Walton and Krabbe (1994?).

7 'Why Sanctions Are Ineffective and Immoral', The Guardian, Wednesday, July 9th, 1986, p. 23.

Lukes, 1987: 183. The other two objections
Lukes advances are specific for the case. One is the $t u$ quoque that "Mrs. Thatcher certainly does not apply this principle elsewhere," and the other points out that "there is compelling evidence that the potential victims of sanctions widely endorse them anyway."

9 Of course one may want to make the terminological decision that a nonfallacious move should not be called ad hominem, but rather, say, personal argument. However, we prefer not to do so. Ater all, the original term is argumentum ad hominem, not fallacia ad hominem, and it has often been used, by John Locke and others, without an implication of fallaciousness.

10 This idea is already present in Barth and Martens (1977). It has been incorporated in the pragma-dialectical approach to the study of argumentation: van Eemeren et al. (1986), van Eemeren and Grootendorst (1987).

11 On types of dialogue see Walton (1992), and Walton and Krabbe (1994? ch. 3).

${ }^{12}$ Cf. van Eemeren et al. $(1986: 158,159)$ and van Eemeren and Grootendorst (1987: 291).

13 Walton (1985) is an extensive study of fallacious and nonfallacious ad hominem arguments. Cf. also Govier (1987: 278), who stresses that argumentative "exchange presumes the sincerity of participants," and that the "insincerity that we infer from pragmatic inconsistency upsets the credibility of the arguer because it leads us to think that he or she is not really participating in an argumentative exchange."

${ }^{14}$ Cf. van Eemeren et al. (1986: 23, Regel 1) and van Eemeren and Grootendorst (1987: 284, Rule I).

15 For simplicity we have not discussed the plurality of models (systems of norms and rules) for critical discussion itself. What is a fallacy according to one model, may not be one according to another, more lenient, model. Cf. Krabbe (1991), and Walton and Krabbe (1994?, chs. 3 and 4). 


\section{References}

Barth, E.M. and J.L. Martens. 1977. Argumentum ad Hominem: From Chaos to Formal Dialectic. The Method of Dialogue-Tableaus as a Tool in the Theory of Fallacy. Logique et Analyse, n.s. 20e Anneé, 76-96.

Brinton, A. 1986. Ethotic Argument. History of Philosophy Quarterly 3, 245-258,

Eemeren, F.H. van et al. 1986. Argumentatieleer 2: Drogredenen [ The Discipline of Argument 2: Fallacies]. Wolters-Noordhoff, Groningen.

Eemeren, F.H. van and R. Grootendorst. 1987. Fallacies in Pragma-Dialectical Perspective. Argumentation 1, 283-301.

Govier, T. 1987. The Social Epistemology of Argument. In: Govier, T., Problems in Argument Analysis and Evaluation. Foris, Dordrecht and Providence, R.I., pp. 271-291.

Krabbe, E.C.W. 1991. Subtypes of Persuasion Dialogue and Dialectical Shifts. In; F.H. van Eemeren et al. (eds.), Proceedings of the Second International Conference on Argumentation. SICSAT, Amsterdam, pp. 371-376.

Krabbe, E.C.W. and D.N. Walton. 1991. Gemakkelijk praten! Situationeel diskwalificerende aanvallen ad hominem, Tijdschrift voor taalbeheersing 13, 108-119.

Lukes, S. 1987. The Morality of Sanctions. The Philosophical Forum 18, 177-184.

Walton, D.N. 1985. Arguer's position. A pragmatic Study of Ad Hominem Attack. Criticism, Refutation, and Fallacy. Greenwood Press, Westport, Conn. and London.
1987. The Ad Hominem Argument as an Informal Fallacy. Argumentation 1, 317-331.

1989. Informal Logic, A Handbook for Critical Argumentation. Cambridge University Press, Cambridge.

1992. Types of Dialogue, Dialectical Shifts and Fallacies. In: F.H. van Eemeren et al. (eds.), Argumentation Iluminated. SICSAT, Amsterdam. pp. 133-147.

Walton, D.N. and E.C.W. Krabbe. 1994? Commitment in Dialogue. Basic Concepts of Interpersonal Reasoning. To be published.

Whately, R. 1829. Elements of Logic, Fellowes, London.

Woods, J. and D.N. Walton. 1977. Ad Hominem. The Philosophical Forum 8, 1-20. Republished in J. Woods and D.N. Walton (1989), pp. 55-73.

1989. Fallacies. Selected Papers 1972-1982.

Foris, Dordrecht and Providence, R.I.

ERIK C.W. KRABBE

FACULTY OF PHILOSOPHY

RIJKSUNIVERSITEIT GRONINGEN

A-WEG 30

9718 CW GRONINGEN, NETHERLANDS

DOUGLAS WALTON

DEPARTMENT OF PHILOSOPHY

UNIVERSITY OF WINNIPEG

WINNIPEG, MANITOBA R3B $2 E 9$ 